\title{
Deep Seated Infection due to Lactobacillus caseii
}

\author{
Maj J M Sloss
}

FRCS(Ed), MRCPath, RAMC

Senior Specialist Pathology

\section{Lt Col N S Cumberland}

PhD, MRCPath, RAMC

Consultant Pathology

The John Boyd Laboratory, Queen Elizabeth Military Hospital, Woolwich, London SE184QH

SUMMARY: A case of intra-abdominal sepsis caused by a vancomycin resistant Lactobacillus is described.

\section{Introduction}

Lactobacilli are normal commensals of both gastrointestinal and genito-urinary tracts. They are very rarely reported as a cause of sepsis $(1,2,3,4,5,6,7,8)$.

This case illustrates the problems that are associated with diagnosis and treatment.

\section{Case Report}

A 79-year-old man was admitted to the Queen Elizabeth Military Hospital with a three week history of right sided abdominal pain. He had a previous history of cholecystectomy and rectal polyp excision six months prior to admission.

On admission examination revealed an unwell elderly man with a pyrexia of $38.5^{\circ} \mathrm{C}$ and signs of left sided heart failure. He had a harsh systolic murmur.

Laboratory investigations showed a leucocytosis of $17.5 \times 10 \%$ (Neutrophils $82 \%$ ), a $C$ reactive protein (CRP) of $109 \mathrm{mg} / \mathrm{l}$ and raised liver enzymes.

Echocardiography demonstrated calcification of the aortic valve, mitral annulus and papillary muscle. Initial blood cultures were sterile.

The initial clinical diagnosis was one of infective endocarditis and treatment was started with parenteral ampicillin and gentamicin. One week after admission he remained unwell with an intermittent pyrexia. Computed tomographic scan (CT) demonstrated an enlarging, multi-loculated intra-abdominal abscess with subhepatic, peri-renal and peri-pancreatic collections. The sub-hepatic abscess was drained and $300 \mathrm{mls}$ of pus was drained using a pig tailed catheter.

Initial Gram stain of this pus revealed gram positive cocci and pus cells. Culture of this grew Lactobacillus caseii ss rhamnosus. Identity confirmed by the Central Public Health Laboratory, Colindale.
Minimum inhibitory concentrations were as follows:

\begin{tabular}{llll}
\hline Ampicillin & $2.0 \mathrm{mg} / 1$ & $\begin{array}{l}\text { Borderline } \\
\text { sensitive }\end{array}$ \\
Gentamicin & $2.0 \mathrm{mg} / 1$ & $\begin{array}{l}\text { Borderline } \\
\text { sensitive }\end{array}$ \\
Methicillin & $32.0 \mathrm{mg} / 1$ & Resistant \\
Vancomycin & $32.0 \mathrm{mg} / 1$ & Resistant \\
Teicoplanin & $16.0 \mathrm{mg} / 1$ & Resistant \\
Ciprofloxacin & $0.6 \mathrm{mg} / 1$ & Sensitive
\end{tabular}

Following initial drainage his clinical condition es- $\frac{3}{5}$ pecially cardiac function improved. However he continued to have a persistent pyrexia and so ciprofloxacin was added to his initial antimicrobial chemotherapy fourteen days after admission. Subsequent drainage of the sub-hepatic abscess was carried out three and five weeks after admission. No organism was cultured from $\underset{\mathscr{D}}{\mathbb{D}}$ pus drained at this time. Ampicillin and gentamicin were $\frac{}{\vec{F}}$ discontinued at three weeks and ciprocloxacin at six weeks. At this point the patient was well, apyrexial and the (CRP) had fallen to $30 \mathrm{mg} / \mathrm{l}$. He was therefore dis- $\delta$ charged.

During follow up a repeat CT scan at four months 윽 revealed a persistent abscess in the right iliac fossa with a $>$ communication to the right hypochondrium. This was successfully drained surgically and the pus obtained was $\mathrm{N}$
sterile.

\section{Discussion}

Lactobacilli are a group of acid resistant Gram-posi- 
tive, non sporing bacilli which occur in the intestine of most mammals being especially numerous during the stage of suckling. They also form the dominant flora of the vagina between menarche and menopause where the ability to ferment glycogen produces an acid $\mathrm{pH}$. In this location they are known as Doderlein's bacilli.

These organisms often have multiple resistance, in particular resistance to vancomycin and teicoplanin is an increasingly important problem $(4,9)$. Most Gram positive organisms are sensitive to vancomycin and teicoplanin and these antibiotics are often recommended in the empirical treatment of gram positive infections and in particular endocarditis(10). Lactobacillus caseiiss rhamnosus was the only organism ever isolated from this patient's intra-abdominal abscess. The portal of entry was presumably at the time of gall bladder surgery. Unlike most previously reported cases this patient was not immunocompromised.

The diagnosis of endocarditis was not proven bacteriologically but there were strong clinical grounds to support the diagnosis and his cardiac problems improved rapidly with chemotherapy. Our initial misidentification on the Gram stain as a Streptococcus is well recognised (7).

This case was unusual in being caused by a vancomycin resistant Lactobacillus which may be an emerging clinical problem(4). It reinforces the necessity of accurately identifying these organisms and determining their antimicrobial susceptibilities.

\section{Acknowledgements}

We wish to thank Lieutenant Colonel W M Melia for permission to report his patient and Mrs M R Greenhan and Mrs C Green for their secretarial assistance.

\section{REFERENCES}

1. Arkin M C, Nicholson L, Harrison G A J, PaUl A, Malink H, Morrison D. Lactobacillus jensenie? prosthetic valve endocarditis. $J$ Infect $1990 ; 21: 322 \vec{F}$ 324.

2. Gopal Rao G, Short A, Carmichael D J S. CAPDי peritonitis caused by vancomycin resistan Lactobacilli. Nephrol Dial Transplant 1990; 5: 235 $\frac{\bar{c}}{\frac{\mathrm{T}}{\alpha}}$ 236.

3. Golledge C. Vancomycin resistant lactobacilli. की Infect 1988; 11: 292.

4. Holliman R E, Bone G P. Vancomycin resistance of clinical isolates of lactobacilli. J Infect 1988; 16: 279-283.

5. Allison D, Galloway A. Empyema of the gallbladder due to Lactobacillus caesi. $J$ Infec⿻ 1988; $17: 191$.

6. Sherman M E, Albrecht M, DeGirolami P C, $e \AA$ al. Lactobacillus. An unusual case of Spleniछు Abscess and Sepsis in an immunocompromise host. Am J Clin Pathol 1987; 88: 659-662.

7. Thornsberry C, FAcklam R R. Vancomycin-re sistant Streptococci? Probably not. Antimicrolo News-let 1984; 1: 63-64.

8. Bayer a S, Chow a w, Betts D, Guze L Lactobacillaemia - a report of nine cases. An Med 1978; 64: 808-813.

9. Johnson A P, UTTley AMC, Woodford \& GEORGE $R$ C. Resistance to vancomycin Teicoplanin: An emerging clinical problem. Micro Rev 3: 289-291.

10. Endocarditis Working Party, BSAC. Lancet 1920 335: 88-89. 